\title{
Protecting children, supporting professionals
}

\section{Hall}

\section{How can clinicians, managers, and national bodies maintain a high standard of child protection work as part of mainstream practice?}

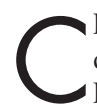
hild protection is for many clinicians an important part of child health practice. Multidisciplinary teamwork in early recognition of child abuse and support for the family may be very rewarding, ${ }^{\prime}$ although paediatric assessment and clinical evidence often play only a minor role. Very few cases involve criminal proceedings or high profile publicity. Yet in recent years the UK paediatricians' professional body, the Royal College of Paediatrics and Child Health (RCPCH), has been aware of more complaints and controversies arising from child protection than from any other area of paediatric practice. Paediatricians have been criticised for ignoring signs of abuse, being over-zealous, making wrong diagnoses of abuse, failing to involve other agencies, upsetting parents, breaching confidentiality, or giving biased evidence in court. Websites criticise doctors and nurses working in child protection, ${ }^{2}$ and the media disseminate libellous inaccurate stories, without fear of reprisal. The unfortunate but predictable result is that professionals are increasingly reluctant to be involved with child protection. ${ }^{3}$

This article considers how clinicians, managers, and national bodies can maintain a high standard of child protection work as part of mainstream practice, support staff and minimise the risk of complaints.

\section{WHAT CLINICIANS CAN DO Appraisal of clinical and research evidence}

Child abuse can masquerade as, and be mistaken for, a wide range of disorders. Missing the diagnosis, or deliberately ignoring it to avoid "getting involved", can spell tragedy for the child. The opposite error, attributing clinical findings to abuse when they are in fact a manifestation of serious disease, is distressing for all concerned but can be largely avoided by consulting colleagues or searching the literature whenever the significance of the findings is uncertain.

\section{Child sexual abuse (CSA)}

The physical examination can be difficult but is usually just part of a wider investigation. Experience takes a long time to acquire and anomalies and abnormalities are difficult to describe accurately, particularly when examining the prepubertal female genitalia. Sketches are easily challenged in court and even when colposcopic photographs are available, there may be disagreements between experts. The over-interpretation of "sexualised behaviours" is also a hazard. ${ }^{45}$

Whether right or wrong, even a suspicion of CSA has a catastrophic effect on the family and the alleged perpetrator. Errors can be minimised by joint planning of the investigation with police and social services. Two observers are better than one. Regular peer review, by examining children in pairs or by review of colposcopic photographs, is probably the best way of reducing error, avoiding over-interpretation of subtle and often insecure physical signs and making it easier to acknowledge uncertainty. ${ }^{6} \mathrm{~Pa}$ rental anxiety and hostility may be reduced by planned follow up and investigation when appropriate. Meticulous physical findings is crucial.

\section{Fabricated and induced illness (FII)}

This is a difficult and often contentious diagnosis. Given the protean manifestations of FII, it is inevitable that sometimes one's initial suspicion will be wrong. Conversely, it is easily missed, particularly if the child is presented to specialists in a variety of disciplines or at different hospitals. Covert video surveillance (CVS) has shown unequivocally how parents can induce serious and sometimes fatal events in their children. ${ }^{7}$ FII is now accepted as a diagnosis, ${ }^{8}$ but has become a focal point of campaigns by aggrieved parent groups. $^{9}$

\section{The clinician as expert witness}

The right to give and to challenge "expert" evidence in court must be documentation of consent and of the preserved, but arguments between experts present social services, the police, and the judiciary with serious dilemmas and greatly increase the difficulty of effective case work with an abusive family. Experts should be familiar with current literature on issues such as the interpretation of growth charts in children with slow weight gain, ${ }^{10}$ the pathogenesis of subdural haematoma and effusion, ${ }^{12}$ or the significance of hypernatraemia, ${ }^{13}$ and must be able to defend their own interpretation of the evidence.

What can be done to minimise bruising encounters in court, which are stressful and time consuming for clinicians and often damaging for the child and family? First, some problems might be avoided if clinicians were more ready to consult their local designated doctor and other colleagues when the clinical findings were unusual or puzzling. Second, doctors should not allow adversarial legal proceedings to force them into polarised positions which may be scientifically unjustified and may not represent their genuine uncertainties. Third, better training and perhaps accreditation of expert witnesses might benefit children and help the judiciary. ${ }^{14}$ This is discussed further below.

\section{Clinical records}

Several complaints against paediatricians have involved accusations of dishonesty, hostility, verbal abuse, and even physical violence against family members. Wherever possible, conversations with parents or carers should take place in the presence of another professional. Detailed, objective, contemporaneous notes of who was present and what was said in every conversation have repeatedly been crucial in the investigation of complaints. Lord Laming stated that there should only be one set of notes, ${ }^{3}$ although some paediatricians feel that, in exceptional circumstances, separate private notes are essential. The policy on this may be governed by local factors such as the security of the ward office or the quality of professional relationships and mutual trust.

\section{Attitudes to multidisciplinary decision making}

All paediatricians experience difficulties in making unbiased judgements about the probability that a particular parent may have abused their child. Professionals need to be aware of their own reactions to the range of emotions and responses exhibited by parents when child protection issues must be confronted..$^{15}$

Abbreviations: CFS, chronic fatigue syndrome; CSA, child sexual abuse; Fll, fabricated and induced illness 
Problems have arisen for clinicians who take on a greater degree of individual responsibility for assessment and management than is necessary. There is often uncertainty surrounding both the clinical findings and the identity of the perpetrator. Clinicians may come under pressure at child protection conferences to be more definite about the clinical features than is justified. The Social Services Department is the statutory body responsible for protecting children and it is the job of the conference to consider all the evidence available. The task of the police is to determine whether a crime has been committed and, if so, by whom. This multiagency approach is particularly vital in complex cases, for instance when multiple victims or perpetrators are involved. ${ }^{16}$

A doctor's duty of care is not necessarily totally discharged by referral to the statutory agencies or even by participation in a case conference, and some paediatricians have experienced difficulties when their own view of the evidence and the need for action has conflicted with that of colleagues in social services or the police. Before taking action in such circumstances, it is wise to consult with colleagues and senior management and to document each conversation and decision.

When there are difficult decisions to be made about returning a possibly abused child to the parents, society has placed the burden of responsibility on the judiciary, not the paediatrician: “... the Court needs all the [paediatric and psychiatric] help it can get. But that dependence in no way compromises the fact that the final decision is the judge's and his alone" ${ }^{14}$ Paediatricians who wish to participate in decision making about intervention and placements must keep up with the substantial body of social sciences research in this field. ${ }^{17}{ }^{18}$

\section{Confidentiality and consent}

The paediatrician's duty of care is first and foremost to the child, not to the parents. If the duty of confidentiality to the parents is in conflict with their duty to the child, the child's interests must come first. A landmark judgment ${ }^{19}$ (which may however go to the Court of Appeal) recently stated that "once suspicion arises about someone who was the mother of a patient, there was a clear duty to investigate in the interests of [the child] ... in fact the doctors could be negligent in certain circumstances to the child if they did not do so ... public policy considerations militate strongly against the existence of any duty of care to [the mother]".

This principle is not universally accepted, however; for example, in a recent General Medical Council (GMC) hearing regarding a child with chronic fatigue syndrome (CFS), the lawyer for the claimant said "Dr X appears to believe that as a consultant paediatrician he had a duty to Miss A, which transcended his duty to follow the wishes of her parents. We submit that in this he was mistaken" (author's italics). In this case, the GMC decided that the doctor was not guilty of serious professional misconduct. Nevertheless, the diagnosis and, more often, the management of CFS have caused difficulties for many paediatricians and some cases have been regarded as a form of FII. This interpretation is often met with outrage by the family, and the courts have in general been reluctant to support it.

It might be unwise to rely too heavily on the judgements mentioned herethey may be overturned. Most paediatricians would probably feel that they can put the child's interests first and yet still take into account the interests and privacy of parents or other adults involved in child protection cases.

Would paediatricians be better protected against such complaints if the reporting of suspected child abuse were to be made mandatory, as in the USA and Australia? Experience from those countries suggests that this would confer some advantages, but also create a number of problems. ${ }^{20}$ Such legislation might make children more reluctant to seek help, both from statutory services and from independent agencies such as Child Line, ${ }^{21}$ since their expressed wish to keep some control of events would no longer be respected. ${ }^{22}$

\section{THE MANAGERS' TASK}

Managers and chief executives of NHS Trusts should ensure that the importance of child protection is recognised in clinical governance policies and that staff are well trained and up to date. They must appoint a Named and Designated Doctor and Nurse as required by Department of Health guidance, and allocate sufficient time and resources for them adequately to provide professional support and to develop policies and training programmes ${ }^{23}$; they must ensure that the policies of the trust are in line with Human Rights legislation and the Data Protection Act; and they must fulfil the requirements set out by the Climbie Enquiry report and the Secretary of State. Lines of accountability to the Trust board must be explicit. They should facilitate the implementation of national guidance regarding interagency work with social services and the police, by supporting joint training. Where feasible, they should provide office space for social services staff on the same site as paediatricians, since this helps to cement good working relationships. Continuous improvement by regular audit and review of procedures should be the aim.

Complaints about child protection work differ in several respects from those about other aspects of patient care and their investigation demands experience and sound judgement on the part of Trust managers. Some of the parents and carers who complain are themselves the subject of a child abuse investigation or criminal enquiry. Deliberate and malicious complaints, sometimes supported by parent groups, are a growing hazard. Complaints are usually directed against the medical team, but the College believes that, if the paediatrician has followed procedures correctly, the responsibility for subsequent actions should properly be shared by the members of the child protection conference and their employing authorities.

\section{THE DUTIES OF THE COLLEGE Supporting doctors and assisting trusts when problems arise}

The College's first duty is to children, not to doctors. It must not publicly defend members who are the subject of investigation, before any enquiries are complete. Doctors working in child protection must be part of a supportive professional network and this needs to be developed both locally, for case review and audit, and nationally, by the College, to provide support and expert advice for doctors who are the subject of complaint and to consider how best to handle the inevitable media interest.

The College assists Trusts in reviewing complaints by providing advice and by careful selection of investigators. It is important to plan and carry out a thorough review from the start-quick and cursory enquiries reach unreliable conclusions; they usually have to be repeated and ultimately prolong the process. Paediatricians who undertake this difficult task must be unbiased and have no fixed a priori positions on key child protection issues. ${ }^{24}$ Furthermore, geography, gender, and ethnicity must be considered; at least two investigators should be involved, with at least one working in a similar setting to that of the doctor being investigated; they must declare any complaints currently against themselves; and they must be thoroughly briefed about terms of reference, indemnity, and the status and ownership of their report. Similarly, any nonmedical chair of a public enquiry or independent review should be politically remote from the local situation, though in reality the College rarely has any control or influence over the choice of chair.

Preparing and disseminating expert reports

The College has published reports on Munchausen syndrome by proxy (FII), ${ }^{25}$ imposed airway obstruction, ${ }^{26}$ and good practice in managing suspected CSA (the latter in collaboration with the Association of Police Surgeons). ${ }^{6}$ The duties of 
primary care organisations in respect of child protection are stressed in guidance to be published by the College early in 2003.* A review is being prepared on confidentiality in child protection work, in partnership with the General Medical Council. Within the College research division, a survey of complaints against doctors in respect of child protection is underway. A systematic review of the physical signs in sexually abused children has been commissioned and will underpin a revision of current guidance. The research division is also completing a review on the practical management of CFS* which, though distinct from child abuse, has sometimes presented paediatricians with child protection dilemmas.

\section{Teaching and training}

A collaborative project is underway with the NSPCC to develop a coordinated approach based on a study guide using a range of articles, pictures, and videos, to ensure that all paediatricians receive theoretical and clinical training in child protection, and an introduction to Children's Rights concepts and legal principles. These topics will feature in College examinations and assessments. The mini-pupillage scheme whereby doctors spend time sitting with a judge in children's cases is beneficial to both professions. ${ }^{14}$ In the USA, fellowships are now available for paediatricians to undertake training and gain experience in child protection ${ }^{27}$ - such a scheme should perhaps be considered in the UK.

Every paediatrician must be prepared to respond to child protection issues as they arise, but we must also develop the next generation of experts and leaders in the subject. Expertise is needed in the mental health and psychiatric aspects of child abuse, domestic violence, ${ }^{28}$ forensic work-by which is meant understanding of the need for objectivity and respect for the rules of evidence-and legal procedures. Mr Justice Wall has stressed the need for a national register of experts and an accreditation process, noting that "parents [may] seek to challenge a multi-disciplinary assessment [and] to obtain permission for an external expert to scrutinise the work of the multidisciplinary team". ${ }^{27}$ The profession also needs a way of dealing with colleagues who present unorthodox theories and misleading reports to the courts. Mr Justice Wall opined that this "must be a matter for the doctors to regulate" ${ }^{27}$

The related goals of protecting paediatricians from unjustified accusations of incompetence, recognising expertise, securing the availability of reliable second opinions, and discrediting unreliable expert witnesses, may best be achieved

*See RCPCH website (www.rcpch.ac.uk) by the creation of an independent system of professional accreditation. In partnership with the Association of Police Surgeons, the College is investigating a scheme hosted by the Council for the Registration of Forensic Practitioners, ${ }^{29}$ a body originally established to avoid miscarriages of justice related to the evidence of forensic scientists.

\section{INFLUENCING POLICY MAKERS}

Workforce shortages and the lack of resources for paediatric and multidisciplinary training will be addressed by national policy development, particularly within the National Service Framework, and by ensuring that chief executives and managers give child protection the priority it deserves-a requirement stressed by Lord Laming in the Victoria Climbié enquiry report. ${ }^{3}$ Complaints procedures regarding child protection cases need to be reviewed-often the issues involve several agencies and it is seldom appropriate to treat these like other NHS complaints. It may be timely to revisit the ways in which our society responds to parents' legitimate concerns about unjustified accusations of abuse, but campaigns involving multiple complainants must be recognised for what they are and the response of the regulatory bodies must be revised."

\section{CONCLUSION}

Child protection will always be a rewarding but difficult and often stressful area of paediatric practice. Paediatricians must be able to engage in the important task of protecting children without feeling that they are putting their careers and their families at risk.

\section{ACKNOWLEDGEMENTS}

I thank Professors Southall, Lynch, and Craft, and Dr Pat Hamilton, for helpful comments and discussion on earlier drafts and on child protection issues in general.

Arch Dis Child 2003;88:557-559

Correspondence to: Professor D Hall, Professor of Community Paediatrics, Institute of General Practice, Northern General Hospital, Sheffield S5 7AU, UK; d.hall@sheffield.ac.uk

\section{REFERENCES}

1 Scottish Executive. Growing support-a review of services for vulnerable families with very young children. Edinburgh: TSO, 2003.

2 MAMA (Mothers against Munchausen syndrome by proxy allegations). www.msbp.com. Accessed 12.03.03.

3 Lord Laming. Inquiry into the death of Victoria Climbie. London: TSO, 2003 (available at www.victoria-climbie-inquiry.org.uk

4 Friedrich WN, Fisher J, Broughton D, et al. Normative sexual behavior in children: a contemporary sample. Pediatrics 1998;101(4 pt 1):E9E99

5 Kools S, Kennedy C. Child sexual abuse treatment: misinterpretation and mismanagement of child sexual behaviour. Child Care Health Dev 2002;28:21 1-18.

6 Royal College of Paediatrics and Child Health and Association of Police Surgeons. Joint guidance on paediatric forensic examinations. London: RCPCH, 2002.

7 Southall D, Plunkett MC, Banks MW, et al Covert video recordings of life-threatening child abuse. Lessons for child protection. Pediatrics 1997; 100:735-60.

8 Department of Health, Department for Education and Employment, and Home Office. Safeguarding children in whom illness is induced or fabricated by carers with parenting responsibilities. London: TSO, 2001.

9 Marcovitch H. GMC must find and deal with vexatious complaints fast. $B M$ 2002;324:167

10 Brosco JP. Weight charts and well child care when the pediatrician became the expert in child health. In: Stern AM, Markel H, eds. Formative years: children's health in the United States 1880-2000. Ann Arbor: University of Michigan Press, 2002:91-120.

11 Wright CM. Identification and management of failure to thrive: a community perspective. Arch Dis Child 2000:82:5-9.

12 Geddes JF, Hackshaw AK, Vowles GH, et al Neuropathology of inflicted head injury in children-I. Patterns of brain damage. Brain 2001;124:1290-8.

13 Coulthard MG, Haycock GB. Distinguishing between salt poisoning and hypernatraemic dehydration in children. $B M$ 2003;326: 157-60

14 The Hon Mr Justice Wall. Expert evidence 10 years after the implementation of the Children Act 1989: where are we? In Rt Hon Lord Justice Thorpe, Cowton C, eds. Delight and dole-the Children Act ten years on. Bristol: Jordan Publishing Ltd, 2002:5-86.

15 Dale P, Green R, Fellows, R. What really happened? London: NSPCC, 2002:40-3.

16 Home Office, and Department of Health. Complex child abuse investigations: inter-agency issues. London: Home Office Communications Directorate, 2002.

17 Jones DPH. The effectiveness of intervention. In: Adcock M, White R, eds. Significant harm: its management and outcome.Croydon: Significant Publications, 1998:91-120.

18 Aldgate J, Statham J. The Children Act now: messages from research. London: Department of Health \& TSO, 2001

19 Dyer C. Paediatricians did not have duty of care to patient's mother. BM 2002;325:1321.

20 Bell L, Tooman P. Mandatory reporting laws: a critical overview. International Journal of Law and the Family 1994;8:337-56.

21 Department of Health. National standards for the provision of children's advocacy services. London: DoH, 2002.

22 NSPCC. NSPCC response to "The national standards for agencies providing advocacy for children and young people in England" London: NSPCC, 2002.

23 Department of Health, Home Office, and Department for Education and Employment. Working together to safeguard children: a guide to inter-agency working to safeguard and promote the welfare of children. London: TSO, 2000.

24 Hey E, Fleming P, Sibert J. Learning from the sad, sorry saga at Stoke. Arch Dis Child 2002;86:1-3.

25 RCPCH. Fabricated or induced illness by carers. London: $\mathrm{RCPCH}, 2002$.

26 BPA Working Party. Evaluation of suspected imposed upper airway obstruction. London: British Paediatric Association, 1994.

27 Evans H. The discovery of child sexual abuse in America. In: Stern AM, Markel H, eds. Formative years: children's health in the United States 1880-2000. Ann Arbor: University of Michigan Press, 2002:233-59.

28 Department of Health. Domestic violence: resource manual for health care professionals. London: DoH, 2000.

29 Council for Registration of Forensic Practitioners. 2003. www.crfp.org.uk Accessed 12.03.03. 